\title{
VIEWPOINT \\ The Old Gods Have Not Abandoned Us
}

Gaetan Sgro, MD

VA Pittsburgh Healthcare System, University of Pittsburgh School of Medicine, Pittsburgh, PA, USA.

$\mathrm{J}$ Gen Intern Med 34(10):2273-4

DOI: $10.1007 / \mathrm{s} 11606-019-05080-\mathrm{w}$

(c) Society of General Internal Medicine 2019

$\mathrm{M}$ uch of the fantasy series "Game of Thrones" concerns the conflict between two dynastic families and their competing ideologies - the "winner take all" ethos of the Lannisters against the heroic decency of the Starks. Of the latter family's patriarch one character notes, "the blood of the First Men still flowed in the veins of the Starks, and his own gods were the old ones."

Physicians today are engaged in a similar clash between our profession's traditional, humanistic values and the demands of the modern marketplace. You can hear it in our language.

I recently attended a talk on diversity and inclusion in academic medicine. A prominent figure in medical education shared a vision of an inclusive culture built on the foundations of social justice and equality of opportunity and urged institutions to revise mission statements and adopt policies to align with these values.

When asked how to resolve the conflict between his vision and the tenets of a free market healthcare system, he explained the need to articulate a "business case" for diversity. In other words, we should accept that the change we seek is viable only if it translates to dollars and cents.

This argument reminded me of the "win-win" approach to philanthropy that pervades "socially conscious" corporations, which the author and former Aspen Institute fellow Anand Giridharadas exposes in his book "Winners Take All: The Elite Charade of Changing the World."

Giridharadas points to the distorted morality implicit in phrases like "doing well by doing good" as a sign that the rules of the marketplace have supplanted traditional religious and enlightenment mores in American culture. He scrutinizes the deference that our society affords the winners, noting: "You can tell the rich and powerful in our

Received January 8, 2019

Revised April 3, 2019

Accepted April 23, 2019

Published online June 10, 2019 age to do more good, but you can never tell them to do less harm. You can tell them to give more, but you can't tell them to take less."

Physicians are reluctantly complicit in a similar bargain. For a chance at the next miracle cure we accept a pharmaceutical company's right to unlimited profit. We stroll glittering corridors and avail ourselves of the latest technology without questioning the sources of such opulence. We swear an oath ${ }^{3}$ that no consideration shall come between our duty and our patients while tacitly endorsing a system that treats healthcare as a commodity.

The values of a culture are embedded in its language and the language of industry has become pervasive. Hospital administrators promote "process improvement" to "manage risk" and meet "quality metrics." Physicians are valued in terms of their clinical and academic "productivity." Today, it is common to hear young doctors speak of "optimizing" patients as if discussing ways to extend a vehicle's battery life.

This is a lexicon devoid of humanity and an underrecognized contributor to medicine's decades-long crisis of meaning. Just as doctors learn that medical jargon can alienate patients, we need to recognize that adopting the language of industry distances us from the original purpose of our work. Similarly, reframing our causes to satisfy the bottom line risks reducing the moral authority of our profession to window dressing.

Though we do not always live up to our ideals, physicians remain grounded in a humanistic tradition that spans millennia. Our faith may waver but the old gods have not abandoned us. We understand the values of the modern marketplace and how inadequate they are when applied to the problem of human suffering. No physician sitting eye to eye with a person in pain has ever dared to articulate a business case.

Physicians may be part of a healthcare industry but we need not be beholden to it. Against discordant incentives we should defend our values vigorously, and for this we must raise our voices and reclaim a lost vocabulary.

Remember: we were called to a life of service, not industry. Remember: we were called to seek justice not because it is profitable but because it is right. Remember: the medicine we offer is more powerful than any 
prescription, deeper than any transaction. We are called to heal. Is there any higher purpose?

Corresponding Author: Gaetan Sgro, MD; VA Pittsburgh Healthcare System University of Pittsburgh School of Medicine, Pittsburgh, PA, USA (e-mail: gaetan.sgro@va.gov).

\section{Compliance with Ethical Standards:}

Conflict of Interest: Dr. Sgro is an Academic Hospitalist at the VA Pittsburgh Healthcare System and a Clinical Assistant Professor of Medicine at the University of Pittsburgh School of Medicine. The author declares that he does not have a conflict of interest.
Disclaimer: The views and opinions expressed in this article are entirely his own and do not necessarily reflect the official policy or position of the Department of Veterans Affairs or any agency of the U.S. government, or the University of Pittsburgh School of Medicine.

\section{REFERENCES}

1. Giridharadas A. Winners Take All: The Elite Charade of Changing the World. New York: Knopf, 2018. Hardcover.

2. Giridharadas A. On Being: When the Market Is Our Only Language Krista Tippett. 15 November 2018. Podcast.

3. RW P-P. "The Revised Declaration of GenevaA Modern-Day Physician's Pledge." JAMA (2017); 318(20):1971-1972.

Publisher's Note Springer Nature remains neutral with regard to jurisdictional claims in published maps and institutional affiliations. 